\title{
Investigation of predictors of injury leading to motorcyclist hospitalization: A case-control study
}

\author{
Shila Hasanzadeh ${ }^{1}$, Mohammad AsghariJafarabadi ${ }^{2}$, HomyounSadeghi-Bazargani ${ }^{3}$ \\ 1. Ns student biostatistics, Department of Statistics and Epidemiology, Research Center, University of Medical Sciences, \\ Tabriz, Iran. ORCID ID:0000-0002-1348-2980 \\ 2. Rofessor in Statistics and Epidemiology, Department of Statistics and Epidemiology, Research Center, University of \\ Medical Sciences, Tabriz, Iran., (Corresponding Author), Tel: 0413-3357580-2 (383),. Email: m.asghari862@gmail.com. \\ ORCID: orcid.org/0000-0003-3284-9749 \\ 3. Asociate Professor in Epidemiology, Road Traffic Injury Research Center, Tabriz University of Medical Sciences, \\ Tabriz, Iran. ORCID: orcid.org/0000-0002-0396-8709
}

\begin{abstract}
Background and Aim: Traffic and its related problems are among the most important public health concerns in the world and prevention of these problems are necessary. GSEM model is a method to test of theoretical models and causal modeling exactly. The objective of the present study was to investigate the predictors of injuries leading to hospitalization of motorcyclists considering MRBQ as a mediator in this case-control study, using a generalized structural equation modeling (GSEM).

Methods: In this case-control study, we selected 303 cases (motorcyclists admitted for a traumatic condition) and 153 controls (motorcyclists admitted for a non-traumatic condition) using a cluster random sampling method in Tabriz, Iran. We used motorcycle-riding behavior questionnaire (MRBQ), Attention-deficit/hyperactivity disorder (ADHD) questionnaire, and a researcher-made checklist. GSEM model was used to examine the direct linear and indirect linear relationships of variables in the conceptual model, considering the binary response variable of the model. Data analysis was performed by STATA14 software.

Results: The predictors of injury were: MRBQ, ADHD, and demographic charcteristics. The results indicated significant linear and direct relationships between odds of injury and cell phone answering $(\mathrm{OR}=2.22, \mathrm{P}=0.010)$, hyperactive child $(\mathrm{OR}=1.65, \mathrm{P}=0.057)$, dark hour riding $(\mathrm{OR}=1.01, \mathrm{P}=0.001)$ and $\mathrm{MRBQ}(\mathrm{OR}=1.27, \mathrm{P}=0.092)$, while there were significant inverse relationships between injury and marital status $(\mathrm{OR}=0.43, \mathrm{P}=0.002)$, and academic education $(\mathrm{OR}=0.29, \mathrm{P}=0.001)$.
\end{abstract}

Conclusions: According to the results of our study, intervention programs on the ADHD, use of cell phone while driving, and dark hour riding are highly recommended.

Keywords: GSEM; Traffic; injury; MRBQ; ADHD

Received: March 13, 2019

Accepted: Feb 25, 2020

How to cite the article: Shila Hasanzadeh, Mohammad AsghariJafarabadi, HomyounSadeghiBazargani. Investigation of predictors of injury leading to motorcyclist hospitalization: A casecontrol study.SJKU. 2021;26(2):114-125.

Copyright (C) 2018 the Author (s). Published by Kurdistan University of Medical Sciences. This is an open access article distributed under the terms of the Creative Commons Attribution-Non-Commercial License 4.0 (CCBYNC), where it is permissible to download, share, remix, transform, and buildup the work provided it is properly cited. The work cannot be used commercially without permission from the journal 


\section{بررسى ييشكويى مصدوميت منجر به بسترى موتورسواران: مطالعه مورد-}

\section{شاهدى}

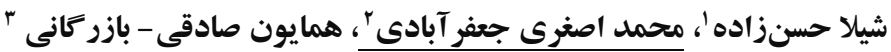

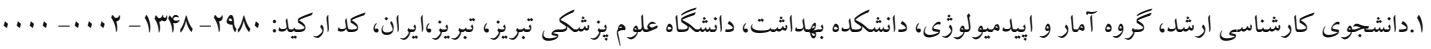

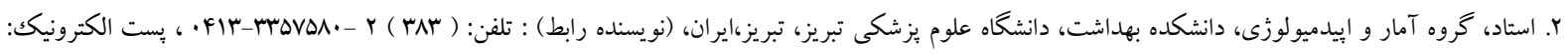
…....r_rYAF_qVFq

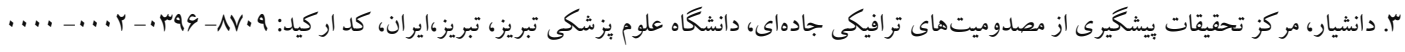

مقدمه و هدف: حو ادث ترافيكى جادهاى يكى از مشكلات جدى بهداشت عمومى در دنيا مىباشد كه بيشخيرى از آن ضرورى

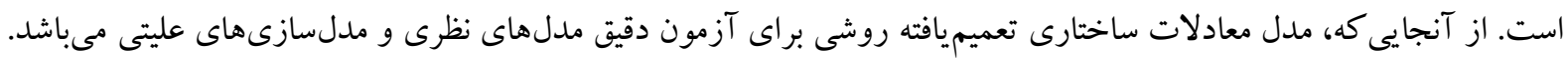

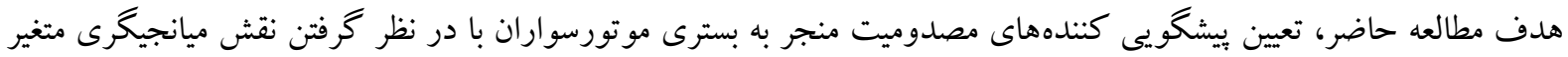
براى متغيرهاى زمينهاى و بيشفعالى در يك مطالعه مورد - شاهدى توسط مدل GSEM مى باشد.

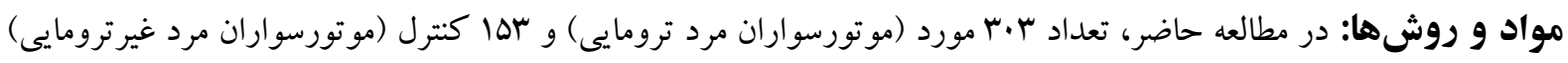

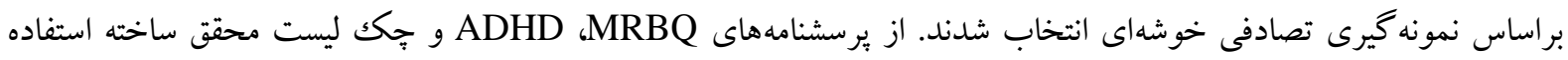

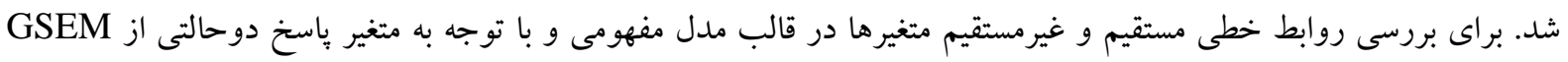

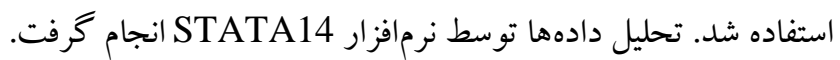

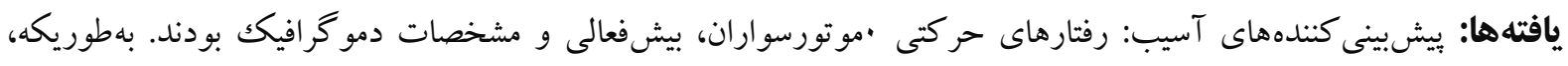

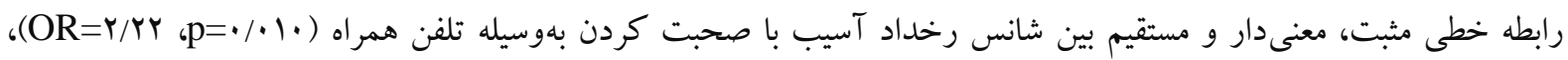

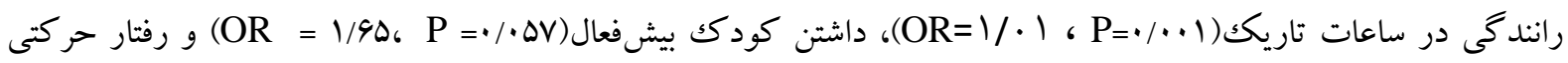

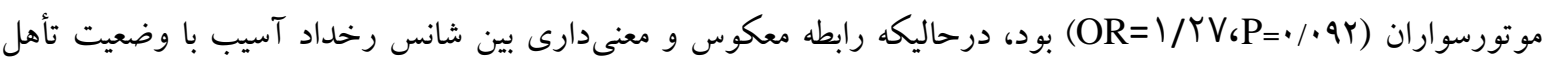

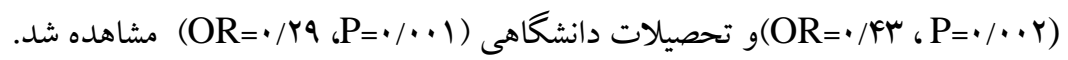
نتيجه كيرى: بر مبناى نتايج بدست آمده، برنامهاى مداخلهاى، درمورد افراد بيشفعال، كسانى كه از تلفن همراه در حين

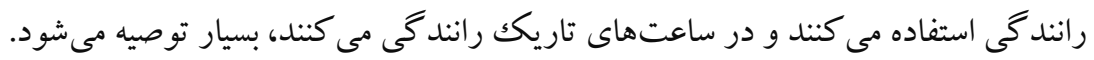
كلمات كليدى: GSEM، ترافيك،، آسيب، ADHD MRBQ

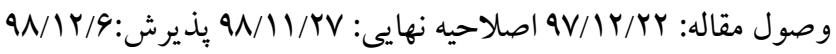


(بارهاى عاملى سازههاى مشاهده شده بر روى متغيرهاى ينهان آنها) مىتوان اشاره كرد. اين مدل علاوه بر فراهم نمودن يك روش كمى براى آزمون نظريه، بر دشوارى تحليل روابط بين متغيرها در بثوهش هاى انسانى فائق آمده

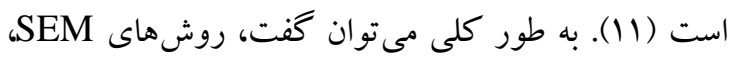

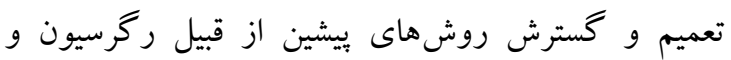
تحليل عاملى است. براساس رويكردهاى مبتنى بر الكوسازى

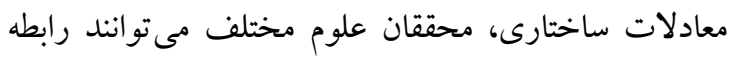

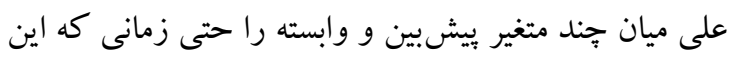

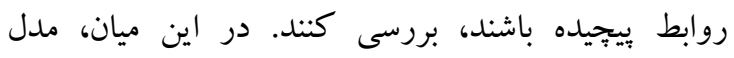

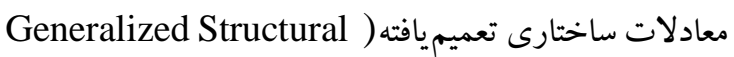
مى تواند براى مدل- Equation Modeling, GSEM هايى با متغير پاسخ دوحالتى نظير مدلهاى رگرسيون

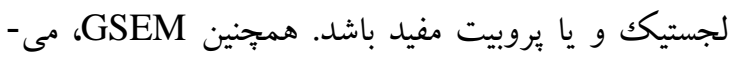

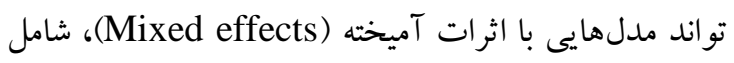

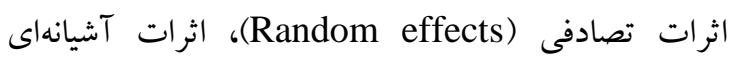
و و اثرات متقاطع (Crossed effects) (Nested effects) را برازش دهد (r)). استفاده از SEM در سالهاى آخير

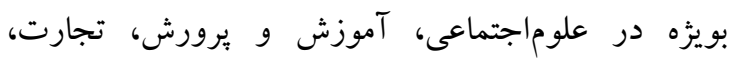

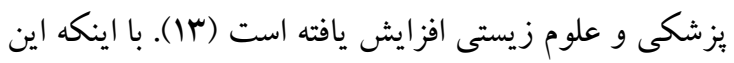

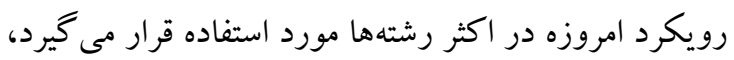

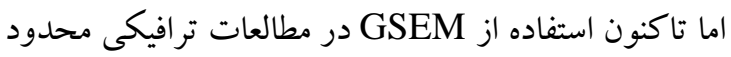
بوده است، هدف مطالعه حاضر، تعيين ميزان بيشكويى تونى GSEM براى مصدوميت منجر به بسترى موتورسواران توسط متغير ميانجى MRBQ است.

\section{مواد و روشها شر كت كند كان}

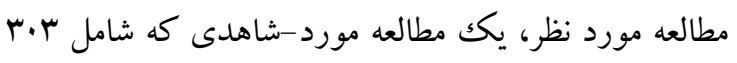

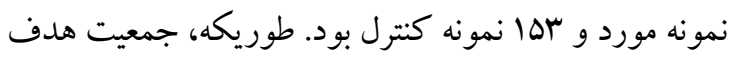

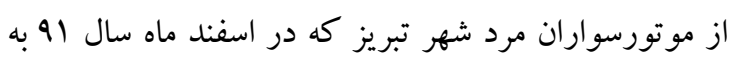

مقدمه

حوادث راندگ مقى به جز خطرات جانى اثرات مهم ديخرى از جمله اثرات روانى به دليل از دست دادن اعضاى خانواده و هزينهاى ناشى از كارافتادگى و ناتوانى، بار سنخينى از هزينههاى اقتصادى را بر جوامع تحميل مى كند (1). حادثه

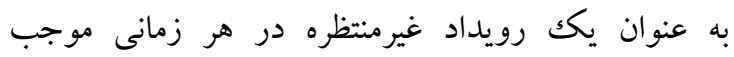
آسيبهاى جسمانى و عوارض روحى و روانى و خسارت-

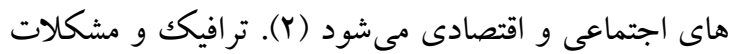
مربوط به آن از مهمترين مسائل جوامع صنعتى بوده كه

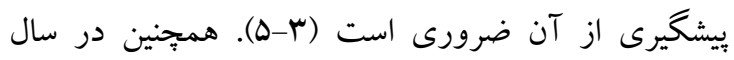

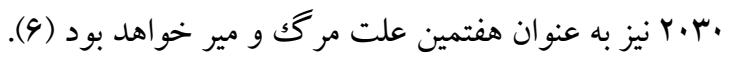
ايران با وجود سير نزولى مركى و مير ناشى از سوانح

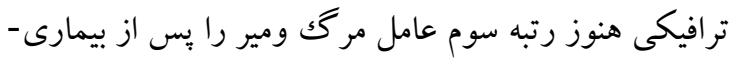

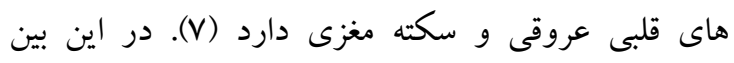

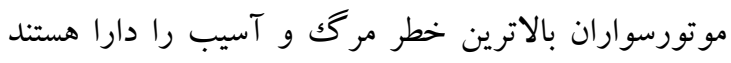

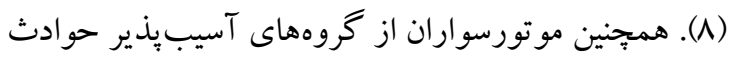

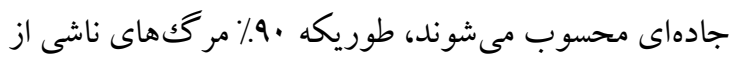
حوادث ترافيكى در كشورهاى با درآمد متوسط و وبايين

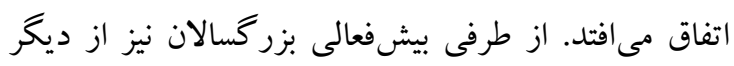

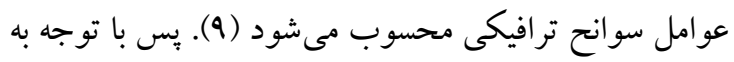

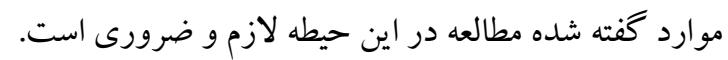

مدلسازى معادلات ساختارى Structural Equation) Modeling, SEM خانواده رگرسيون جندمتغيره است به محقق امكان مىدهد مجموعهاى از معادلات رگرسيونى را كه بهطور همزمان تعريف شده، در قالب يكك مدل مفهومى مورد آزمون قرار

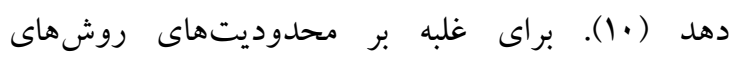
ركرسيونى شامل خطاى اندازهگيرى مربوط به متغيرينهان،

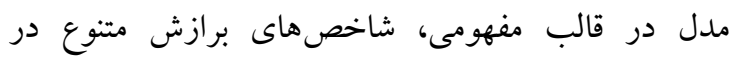
SEM

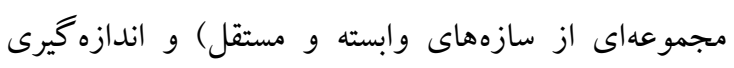


IIV Sمدد اصغرى بعفرآبادى

كزارشدهى كانرز كه براى غربالكرى بيشفعالى

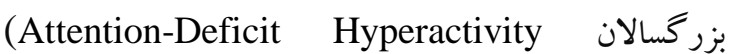
كاربرد دارد و شامل جندين (Disorder, ADHD زيرمقياس براى غربالكرى و درمان بيماران شاخص اختلال

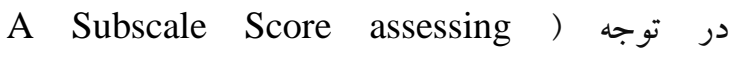
B ) (inattention, ASS Subscale Score assessing hyperactivity, توكان (impulsivity, BSS C subscale C the sum of A ) تكانشخرى-بيش و شاخص اختلال بيش فعالى و (and B subscales, CSS عدم توجه ( D subscale score assessing ADHD (index, DSS است و در تبريز ترجمه شده و روايى و ״ايايى آن توسط دكتر اميرى و همكاران انجام شده (F)

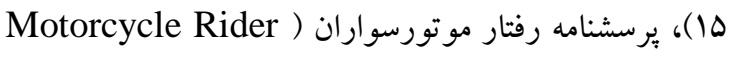
Behavior Questionnaire, MRBQ

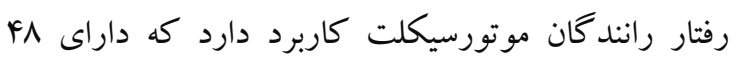

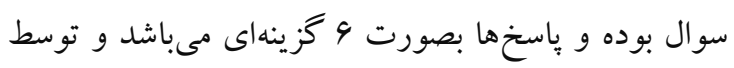
دكتر متوليان در تهران ترجمه و روايى و ويايايى آن انجام شده است (IV, IV ) و جـك ليست محقق ساخته كه شامل

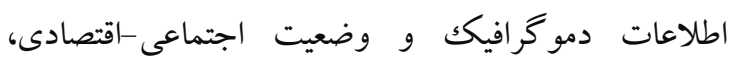

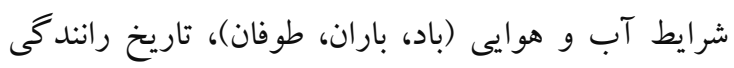

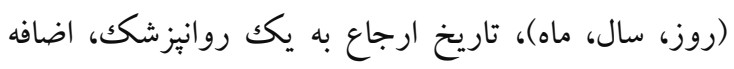

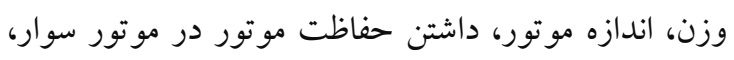
هدف استفاده از موتور بود، استفاده شد.

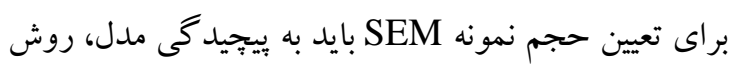

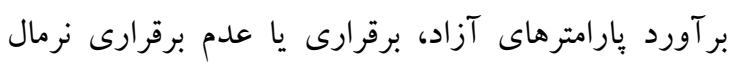

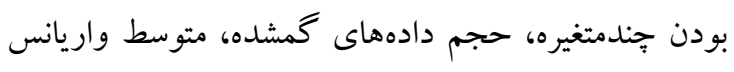

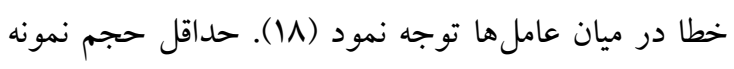

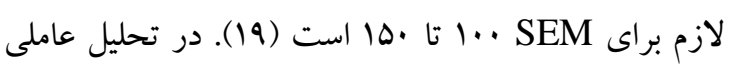
تأييدى حداقل حجم نمونه براساس عامل ها تعيين مى شود نه

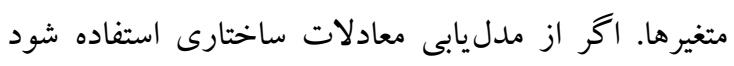

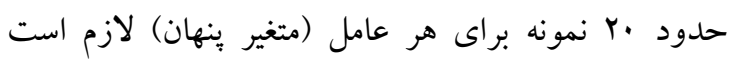

بيمارستان شهدا و امام رضا مراجعه كرده بودند، انتخاب شدند. موردها از بين موتورسوارن مجروح بسترى شده در دو

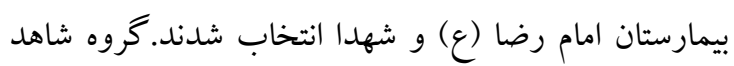
مناسب از سيستم طبقهبندى كديستى شهر، كه در بروزه ونها جامعهى ايمن شهر تبريز و طرح حاكميت بالينى استفاده

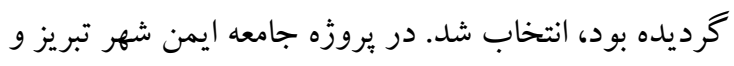

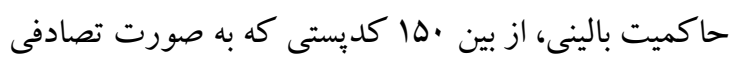

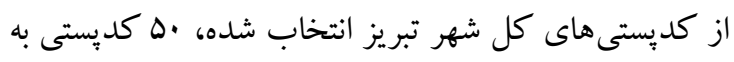

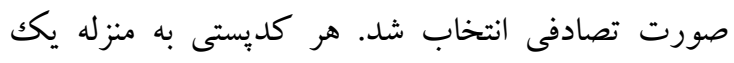

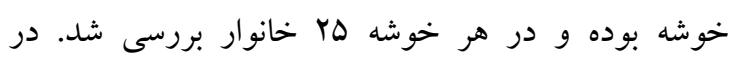
ير سشنامه بروزهه جامعه ايمن، بخشى وجود دارد كه بر برسخر از فرد مصاحبه شده در مورد اينكه موتور دارد يا ندارد

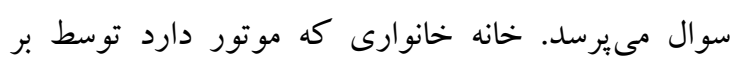

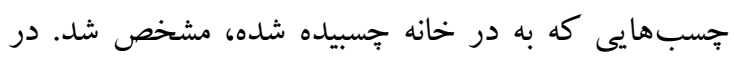

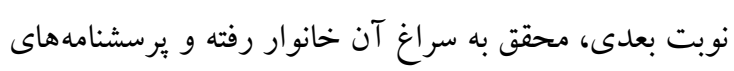

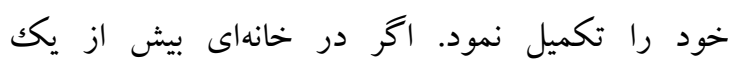
موتورسوار وجود داشت، محقق به تصادف موتورسوارى را

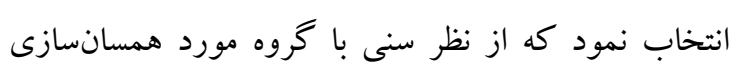

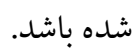
معيارهاى ورود به مطالعه براى گروه مورد: افراد هوشيار به هنگام يركردن برسشنامه و مجروح در بيمارستان بودند.

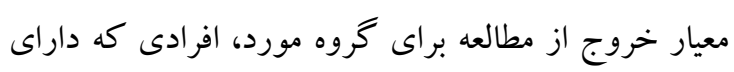
هوشيارى پايين به علت ضربه مغزى داشتند، راننده موتور

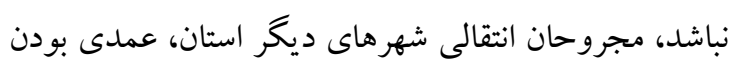

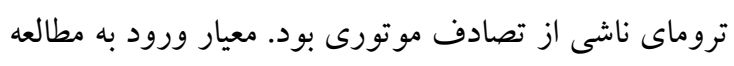

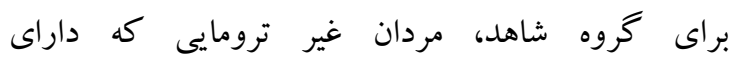
موتورسيكلت بودند و معيار خروج از مطالعه براى گروه ترهان

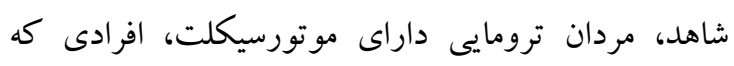
داراى تاريخجه بسترى در بيمارستان به خاطر تروما بودند.

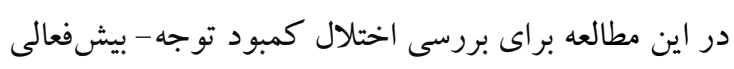

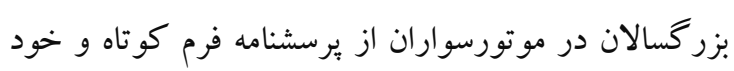


شدند، مرحله سوم از روش برآورد حداكثردرستمايى استفاده شد، مرحله جهارم ارزيابى مدل توسط شاخصهاى برازش (كاىدو بر درجه آزادى Normed Chi2) (كمتر از ه يا r، شاخص برازندگى تطبيقى (Comparative Fit) Tucker-Lewis و شاخص تاكر - لويس Index, CFI) بيشتر از 9.9. Index, TLI ) خطاى برآورد ( Root Mean Square Error of Approximation, RMSE) ريشه ميانگين مربعات باقيمانده استاندارد Standardized) Root Mean Square Residual, SRMR ه./.)، مقايسه مدلهاى ساختارى و اندازه گيرى با حضور و بدون متغير ميانجى MRBQ نيز توسط معيار اطلاعات آكائيك (Akike Information Criterion, AIC) و معيار اطلاعات بيزى Bayesian Information Criterion, BIC) از شاخصهاى اصلاح مدل استفاده گرديد.

يافتهها

نمونه نهايى شامل FDA موتورسوار مرد در شهر تبريز كه

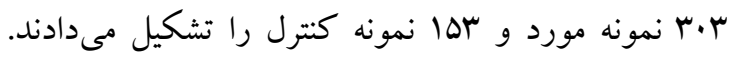
ميانگين سنى در گروه مورد و شاهد به ترتيب ل11/VV ه/ ץ//

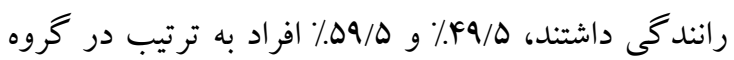

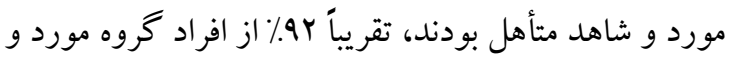
VQ\% از افراد گروه شاهد تحصيلات دانشكاهى نداشتند و

$$
\text { ساير مشخصات در جدول اكزارش شد. }
$$

(Y.) حجم نمونه توصيه شده براى تحليل عامل تأييدى

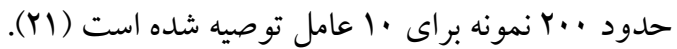

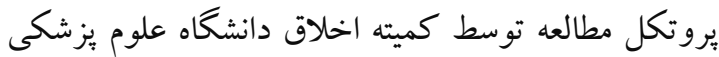
تبريز) (ethic code: TBAMED. REC.1394.783) تصويب گرديد. همه شركت كند كان رضايت و موافقت آكاهانه را تكميل و امضا كردند.

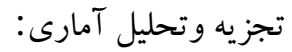
متغيرهاى مستقل و ويش بينى كنندهاى مورد استفاده در اين تحقيق وضعيت تأهل (متأهل / مجرد)، سطح تحصيلات

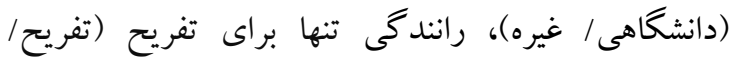
غيره)، گو اهينامه راندگى (بله/ خير)، سابقه رانندگى (بله/ خير)، راندگى در هواى تاريك (بله/ خير)، اندازه

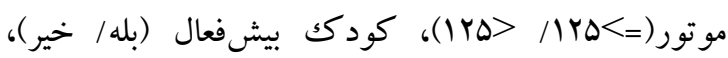

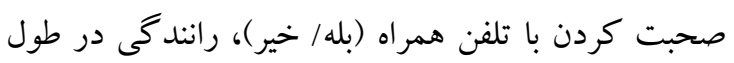
هفته (بله/ خير)، استفاده از كلاه ايمنى (بله/ خير)، استفاده از

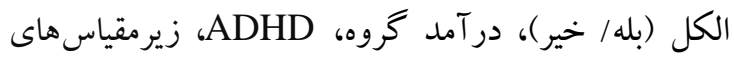
ADHD CSS (ASS+BSS) و متغير وابسته دوحالتى (آسيب) مورد بررسى و (MRBQ)

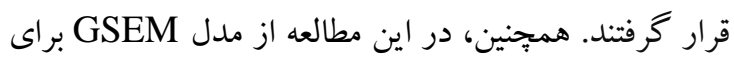
نشان دادن مدل در قالب مفهومى و ارزيابى روابط متغيرها

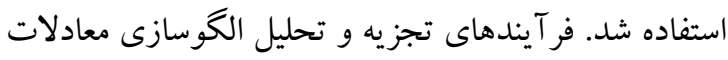
ساختارى كه توسط نرمافزار MPLUS7.4 و انجام گرفت، شامل مراحل: مشخصات مدل، ترم: شناسايى مدل، بر آورد مدل، آزمون مدل و اصلاح مدل

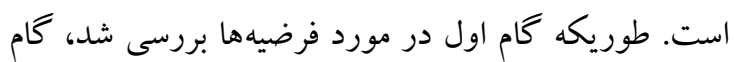

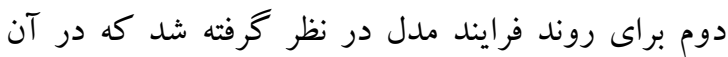
تعدادى از يارامترهاى ورودى و خروجى به ترتيب انتخاب

جدول ا: مشخصات توصيفى شركت كنند كان در مطالعه، فراوانى و درصد آسيب در هر سطح از متغيرهاى يبش ينى شده به تفكيك كروه موردو شاهد (No7)

\begin{tabular}{|c|c|c|}
\hline كروه شـاهد N(\%) & אروه مورد N(\%) & متغير ها \\
\hline & & داشتن گواهينامه رانند گى \\
\hline$\Delta r(M F / 9)$ & $G \Lambda(Y Y / Y)$ & بله \\
\hline $9 \wedge(9 F / 1)$ & rmD (VV/9) & خير \\
\hline & & سابقه راند گى \\
\hline $1 \% q(\Lambda F / \Gamma)$ & YVD $(q \cdot / \wedge)$ & > اسال \\
\hline
\end{tabular}


119 مaمد امغرى بعفرآبادى

\begin{tabular}{|c|c|c|}
\hline$Y F(I \Delta / V)$ & $r \wedge(Q / Y)$ & > > اسال \\
\hline & & وضعيت تأهل \\
\hline$\Delta Q($ (ץ/9) & $10 \cdot(F q / \Delta)$ & 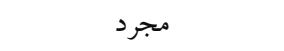 \\
\hline \multirow[t]{2}{*}{$91(\Delta Q / \Delta)$} & $10 \cdot(F q / \Delta)$ & متأهل \\
\hline & & تحصيلات دانشگاهى \\
\hline$I r \cdot(V \Lambda / F)$ & rVG $(91 / 1)$ & 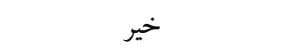 \\
\hline \multirow[t]{2}{*}{$M(Y \backslash / 9)$} & rV $(\Lambda / 9)$ & بله \\
\hline & & راندكى فقط براى تفريح \\
\hline Irr $(\Lambda g / \Gamma)$ & 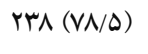 & خير \\
\hline \multirow[t]{2}{*}{$r \mid(I r / V)$} & $90(Y \backslash / \Delta)$ & بله \\
\hline & & اندازه موتور \\
\hline \multirow[t]{2}{*}{$a F(G \mid / F)$} & $r M V(V \Lambda / Y)$ & كمتر يا مساوى Iroا سى \\
\hline & & سى \\
\hline \multirow[t]{2}{*}{$\Delta q($ (r/q) } & $99(Y \backslash / \Lambda)$ & بيشتر از ها سى سى س \\
\hline & & داشتن مشكل روانى \\
\hline$r r(1 \Delta / \cdot)$ & $10(\Delta / \cdot)$ & بله \\
\hline \multirow[t]{2}{*}{$\mid r \cdot(\Lambda \Delta / \cdot)$} & $Y M(9 \Delta / \cdot)$ & خير ي \\
\hline & & جواب دادن به تلفن همر اه \\
\hline$F V(r \cdot / V)$ & $\operatorname{lgr}(\Delta r / \Delta)$ & خير \\
\hline \multirow[t]{2}{*}{$1 . r(99 / V)$} & $\| \Gamma(r V / \Gamma)$ & بله \\
\hline & & سيگار كشيدن \\
\hline$\Lambda F(\Delta F / q)$ & $M M(G Y / \cdot)$ & خير \\
\hline \multirow[t]{2}{*}{$99(F \Delta / 1)$} & $110(r \Lambda / \cdot)$ & بله \\
\hline & & در آمد گروه \\
\hline$F F(Y \wedge / \Lambda)$ & $\operatorname{IrF}(F \cdot / 9)$ & كمتر از ·. له هزار تومان \\
\hline$\Lambda \Delta(\Delta \Delta / 4)$ & $|\Psi|(F / Y)$ & 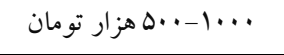 \\
\hline \multirow[t]{2}{*}{$Y F(\mid \Delta / V)$} & $F \wedge(\mid \Delta / \Lambda)$ & بيشتر از ... اهزار تومان \\
\hline & & داشتن كودكك بيشفعال \\
\hline$G r(F, / Y)$ & $M M(G Y / \cdot)$ & 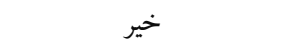 \\
\hline \multirow[t]{2}{*}{$V \cdot(F \Delta / \Lambda)$} & $99(\mathrm{YI} / \mathrm{V})$ & بله \\
\hline & & مصرف ساليانه مواد مخدر \\
\hline $9 \Delta(9 Y / 1)$ & $\operatorname{rrT}(V / 9)$ & خ ت بير \\
\hline \multirow[t]{2}{*}{$\Delta \wedge(Y V / q)$} & $\Lambda \cdot(Y q / \mathcal{F})$ & ل \\
\hline & & كو اهينامه موتورسيكلت \\
\hline $\operatorname{Irr}(\Lambda g / \Gamma)$ & $r V \cdot(\Lambda q / 1)$ & 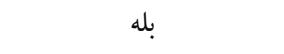 \\
\hline$\wedge(\Delta / Y)$ & rq $(N / 9)$ & 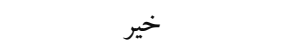 \\
\hline & & استفاده كردن از كلاه \\
\hline
\end{tabular}


\% برارس بيشكويى sمدوميت...

\begin{tabular}{|c|c|c|}
\hline GV (FY/A) & $\operatorname{IrF}(F \cdot / 9)$ & بله \\
\hline \multirow[t]{2}{*}{ 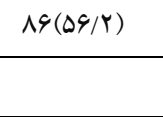 } & 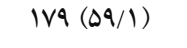 & خير \\
\hline & & مصرف الكل \\
\hline If $(9 / Y)$ & $\|(F / \Gamma)$ & بله \\
\hline \multirow[t]{2}{*}{$1+9(9 \cdot / 1)$} & $r q \cdot(q \Delta / V)$ & خير \\
\hline & & داشتن عينك \\
\hline$M r(Y \cdot / 9)$ & $r V(I Y / Y)$ & بله \\
\hline$\| Y(V Y / Y)$ & r\&D (AV/D) & خير \\
\hline$r \cdot / N r \pm N / 91$ & $r Q / r \Lambda \pm \| / N V$ & ميانگين سن \\
\hline $10 \%(1 .)$. & $r \cdot r(1 \cdot \cdot)$ & جمع \\
\hline
\end{tabular}

مدلهاى مختلفى با حضور و بدون متغير ميانجى (MRBQ) لحاظ گرديد و در نهايت مدلها توسط AIC و مقايسه كرديدند و مدل بهينه ارائه شد (مدلى كه در آن مدل بهعنوان متغير ميانجى باشد) (جدول MRBQ

. (r
در مطالعه حاضر از مدل GSEM براى لحاظ كردن روابط همزمان بين متغيرها در قالب مدل مفهومى استفاده شد. كه متغيرهاى (وضعيت تأهل، سطح تحصيلات، رانندگى در ساعات تاريك، صحبت كردن با تلفن همراه، داشتن كودك بيشفعال با آسيب) معنى دار بودند. همجنين براى رابطه ADHD ،MRBQ و عوامل زمينهاى با آسيب

جدول r: مقايسه مدلها توسط شاخص AIC و BIC براى متغير ADHD با واسطه و بدون واسطه

\begin{tabular}{|c|c|c|}
\hline BIC & AIC & مدلها \\
\hline$|Y| G V / Y 4$ & IIGTr/rA & مدل اول \\
\hline $\mid V \Delta \wedge q / \Delta r$ & IVAFG/YD & مدل دوم \\
\hline$|r r| F / \Delta r$ & $119 \mathrm{Vq} / \Delta \mathrm{r}$ & مدل سوم \\
\hline IVA9F/9R & $|V \wedge Q F / Y|$ & مدل جهارم \\
\hline
\end{tabular}

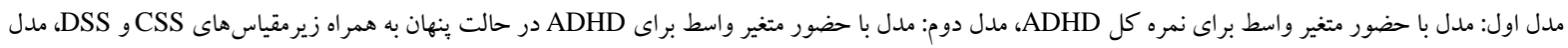

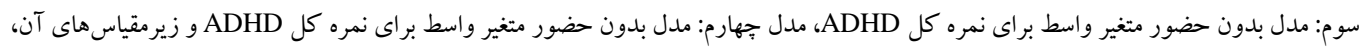
ADHD

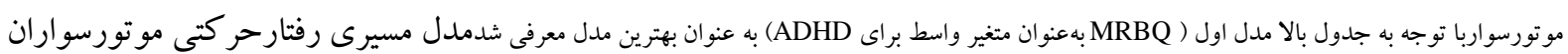
بهعنو ان متغير ميانجى براى نمره كل بيشفعالى بزر كسالان و ارتباط مستقيم متغير ميانجى با متغيرياسخ لحاظ شد. طوريكه، مدل از

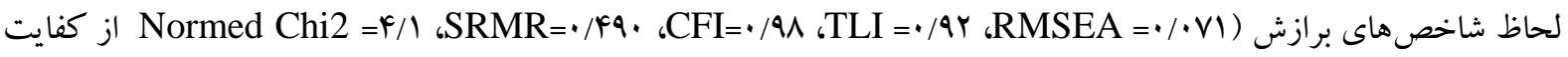
لازم برخوردار بود و تمامى متغيرها غير از سابقه موتورسوارى در مطالعه حاضر معنىدار بودند ( ( P> P).( شكل I) 


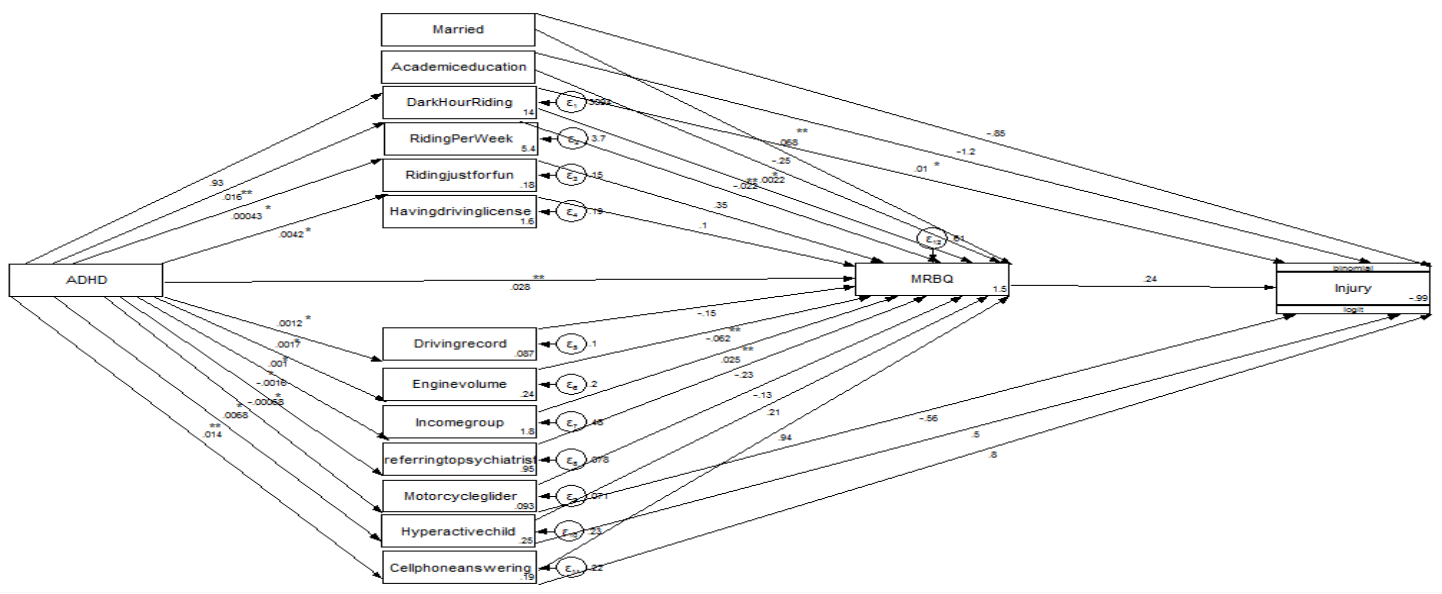

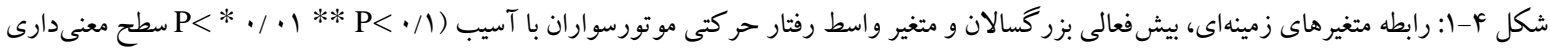

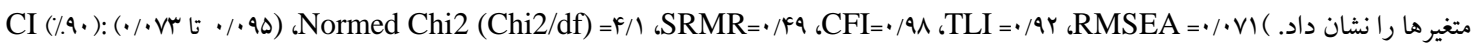
نتايج بدست آمده از شكل بالا نشان داد كه رابطه خطى الى كه رابطه معكوس و معنىدارى بين شانس رخداد مثبت، معنى دار و مستقيم بين شانس رخداد آسيب باصحبت آسيب با وضعيت تأهل و تحصيلات دانشگاهى بود

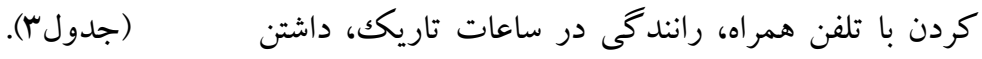
كودك بيشفعال و رفتار حركتى موتورسواران بود، در

جدول r: نتايج بررسى رابطه شانس رخداد آسيب با متغيرهاى زمينه اى و رفتار موتورسواران

\begin{tabular}{|c|c|c|c|c|c|}
\hline P-Value & $\mathbf{Z}$ & $\mathbf{S E}$ & CI $(90 \%)$ & $\operatorname{Exp}(B)$ & آسيب \\
\hline$\cdot \cdot \cdot r$ & $-r / .4$ &.$/ 119$ & $(\cdot / Y V I, \cdot / 9 V 9)$ &.$/ 4 \pi$ & وضعيت تأهل \\
\hline$<\cdot / \cdot \cdot 1$ & $-r / \notin q$ & $\cdot 1 / 4$ & $(\cdot / 1 G Y, \cdot / \Delta Y Y)$ & $\cdot / 79$ & تحصيلات \\
\hline$<\cdot / \cdot \cdot 1$ & $r / \cdot r$ & $\%$ & $(1 / \cdot .4,1 / \cdot 14)$ & $1 / \cdot 1$ & راندگگى درساعات تاريك \\
\hline$\cdot / T \Delta F$ & $-1 / 1 f$ & $\cdot / T A \mid$ & $(\cdot / r \Delta F, I / Y \wedge Y)$ & $\cdot / \Delta \mathrm{V}$ & سابقه مو تورسو ارى \\
\hline$\cdot / \cdot \Delta V$ & $1 / 9$. & . & $(1 / \cdot V \cdot, r / \Delta F \Lambda)$ & 1/90 & كو دكى بيشفعال \\
\hline .1 .1 & $r / \Delta V$ & .1994 & $(1 / r \mu r, r / V \cdot \Lambda)$ & r/Yr & صحبت كردن با تلفن همراه \\
\hline.$/ .94$ & $1 / 91$ & . /MAF & $(1 / . .9,1 / 91 V)$ & $1 / \Upsilon \wedge$ & رفتارحر كتى مو تورسو اران \\
\hline
\end{tabular}


رفتارى (تأييد مدل مربوط به برسشنامه كانرز ADHD) و تحليل روابط بسيار بيجيده داشته باشد (YD). نتايج مطالعات ديخرى نيز كه توسط Pour Ahmad A و همكاران در سال IRaykov T و همكاران در سال rا.بr و نشان دادند كه براى اهداف توسعه مبانى نظرى (تحقيقات تئوريكك) بهتر است از مدل SEM استفاده شود و SEM يكى از ابزارهاى كمى و جِندمتغيره است كه به بررسى و ارزيابى برازش مدل برداخته است، گامى در تعيين ميزان

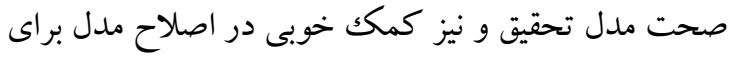

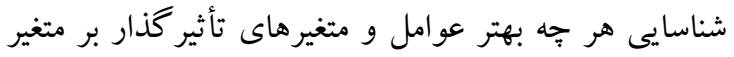

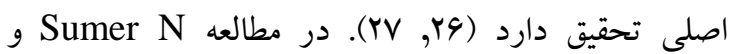
همكاران در سال r..r همراستاى نتايج مطالعه حاضر، نيز

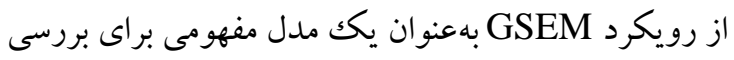

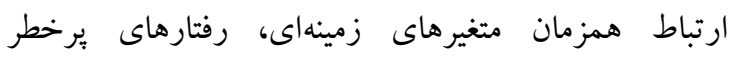

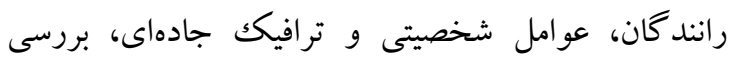
روابط مستقيم و غيرمستقيم با وجود متغير ميانجى و بيش-

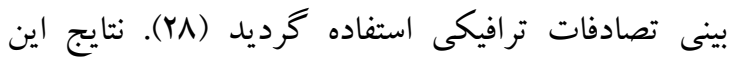

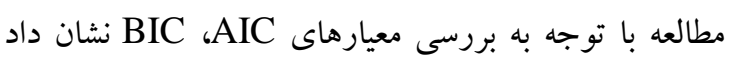
كه نمره كل ADHD براى ارزيابى ارتباط با آسيب در مقايسه با زمانى كه ADHD يكك متغير بنهان با زير مقياس بـ

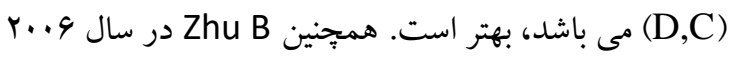
در مطالعهاى با توجه به r//RR=1/ نشان داد كه اختلال

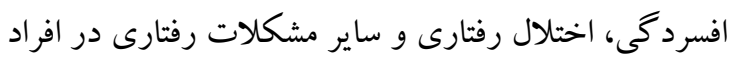

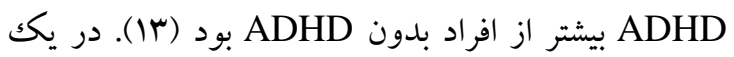

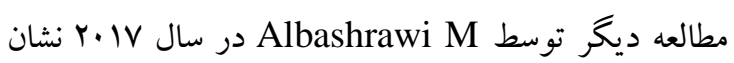

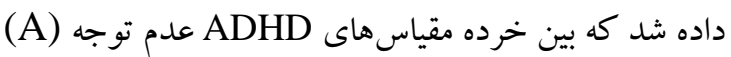

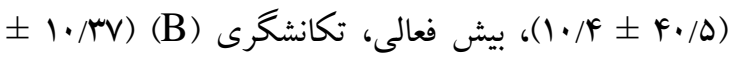

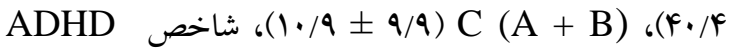

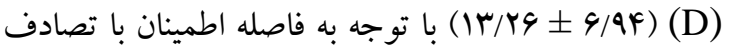
رابطه معنادارى وجود داشت (Y9). نتايج ديخر اين مطالعه نشان داد كه بين تحصيلات و آسيبهاى موتورسيكلت رابطه معنى دارى وجود دارد به طورى كه افراد تحصيلكرده Alinia از افراد ديخر كمتر آسيب مى بينتد، نتايج مطالعات

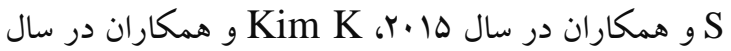

نتايج مطالعه حاضر نشان داد كه براى بررسى روابط مستقيم

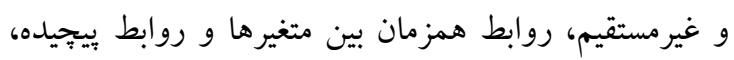

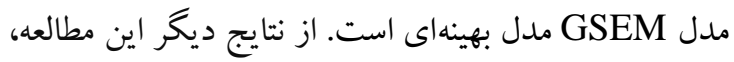
MRBQ به عنوان متغير ميانجى براى ساير متغيرها است.

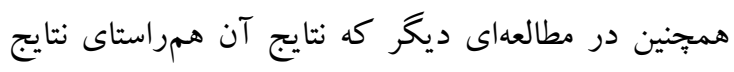

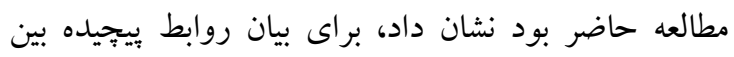

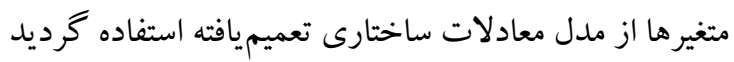
زيرا اين مدل مى تواند به طور همزمان از متغيرهاى درونزاد مداد

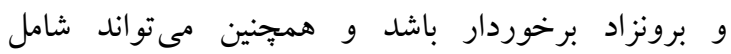

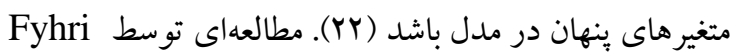

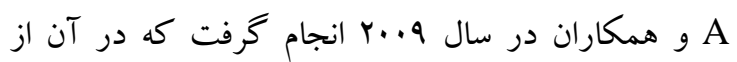
روش مدلسازى معادلات ساختارى تعميميافته براى بررسى

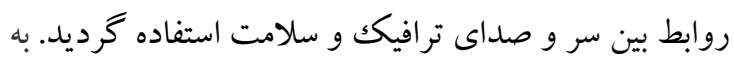
طور دقيقتر، ارتباط بين شكايات سر و صدا، حساسيت و

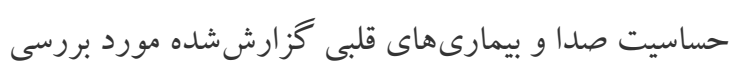

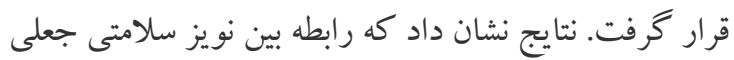

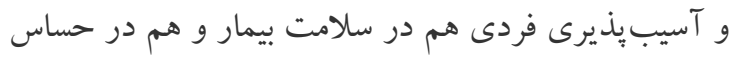
بودن به صدا تاثير داشت (Yr). در مطالعهاى نيز كه توسط Alavi M GSEM به دليل دارا بودن قابليتهاى متعدد (بررسى ارتباط همزمان بين متغيرها، روابط بيجيجيده متغيرها و لحاظ كردن متغيرهاى بنهان در مدل) و نيز غلبه بر محدوديتهاى روشهاى سنتى كاربردهاى بسيارى در مطالعات ترافيكى و علوم انسانى داشت (YF). نتايج يكى ديكر از مطالعات توسط Mogadasin M و همكاران در سال rا.بr كه مشابه نتايج مطالعه حاضر بود نشان داد، از آنجايى كه شامل هر دو مدل اندازه گيرى (ارتباط بين متغيرهاى مشاهده شده و آيتم سازنده هر متغير) و ساختارى (ارتباط

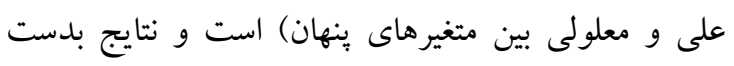

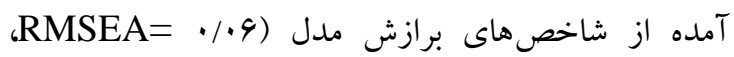

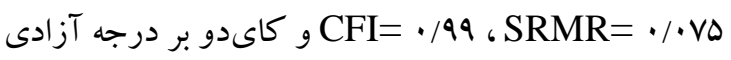
برابر Y/FA) مىتواند كاربرد زيادى در دادهاى علوم 
اين روش را محدود مىسازد (YN). بهصورت ابتدايى، روابط غير خطى و اثرات متقابل رادر مدل لحاظ نمىكند.نياز است كه بيش فرضهاى ورئ ركرسيون ازجمله نرمال

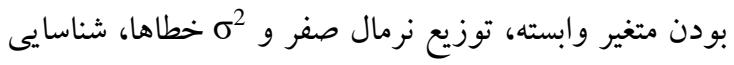

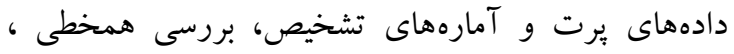
بررسى استقلال خطاها، داشتن حجم نمونه و مناسب بودن آن با توجه به تعداد متغيرهاى بيشبينى برقرار باشد (هو). زمانى كه متغير پاسخ دوحالتى باشد مىتوان از استفاده كرد، تفسير خروجى متغيرها مشكل است. يكى ديخر از محدوديتهاى مطالعه حاضر، عدم تعادل تعداد نمونه در گروههاست (تعداد نمونههاى گروه شاهد تقريباً نصف گروه مورد مىباشد). از طرفى جون نمونه گيرى از داخل شهر تبريز انجام گرفته شد تعميم به جوامع بزر كتر امكان بذير نيست. مطالعات بيشتر در آينده توسط مدل

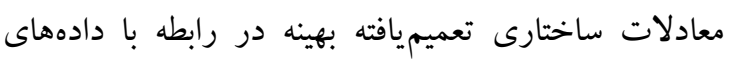

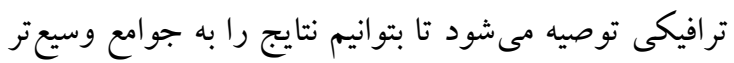

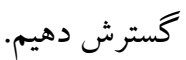

\section{نتيجه كيرى}

با توجه به نتايج بدست آمده از مدل GSEM برنامههاى مداخلهاى در مورد كود كان بيشفعال، افرادى كه در هنگًام رانندگى با تلفن همراه صحبت مى كنند، افرادى كه در

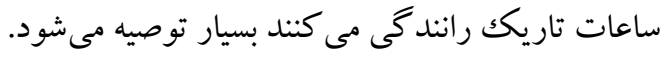

\section{تشكر و قدردانى}

از اعضاى محترم هيأت علمى گروه آمار و إيدميولوزى دانشكده بهداشت و تغذيه و معاونت تحقيقات و فناورى

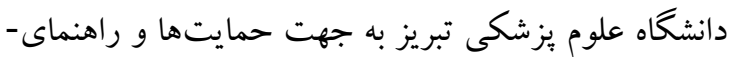
هاى ايشان در اين تحقيق، تشكر و قدردانى مى شودد.

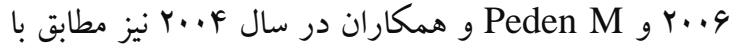
مطالعه حاضر بود (·r-rYr). مطالعه حاضر نشان داد كه بين كود كان بيشفعال و آسيب رابطه معنىدارى بود. مطالعهاى نيز كه توسط Albashrawi M در سال IV Y نشان داد كه رابطه معنىدارى بين ADHD در كودكان و والدين آنها وجود دارد كه نيازمند درمان در دوران كودكى است و والدين با كودكان ADHD در معرض خطر آسيب بيشترى نسبت به والدين كودكان بدون ADHD قرار دارند (Y9).

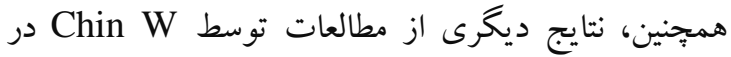

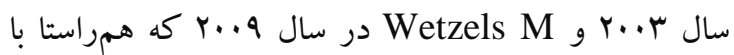
مطالعه حاضر بود، بيانگر اين بود كه رانندگى در ساعات تاريك،، رانندگى فقط جهت تفريح استفاده از تلفن همراه

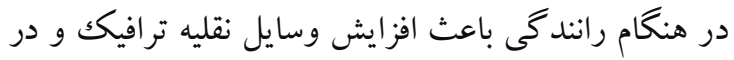

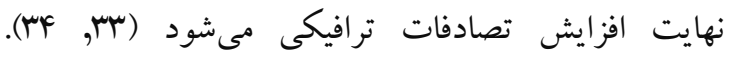

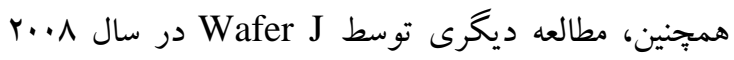

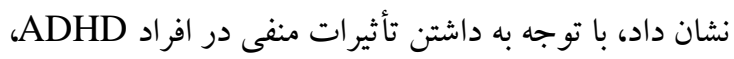

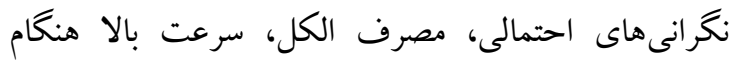

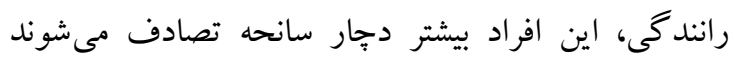

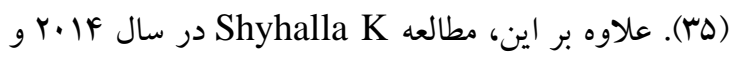
Weiss H

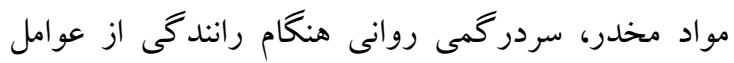

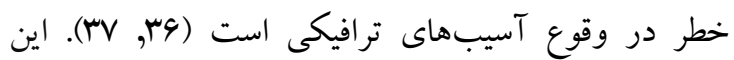

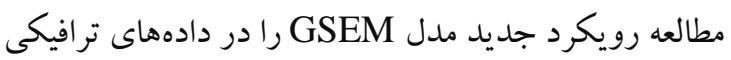
براى يكى مطالعه مورد-شاهدى لحاظ مى كند تا اينكه موتورسواران امكان استفاده از اين مدل بهينه را داشته باشند.

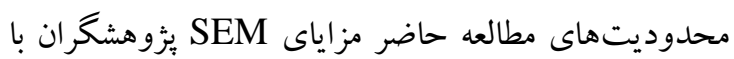
محدوديت هاى مختلفى در استفاده از مدل مذكور دارند:نياز به وجود نظريههاى دقيق و شواهد تجربى است، كه كاربرد

منابع 1.AsF. GBGS. Relationship between attitude, personality traits and perceived control source with a variety of driving behaviors,. Journal of Health and Development ,. 2014;;3(1):48-61.

2.Baghiyani Maghadam MH ZR GJ, Dashti M, Aram M,. Indagate attitude and Performance Yazd motorcyclists to use helmets. 2010, . 
3.LA. MC. Global Health Statistics: a compendium of incidence, prevalence and mortality estimates for over 200 conditions. 1996,.

4.Odero W, Khayesi M, Heda P. Road traffic injuries in Kenya: magnitude, causes and status of intervention. Injury control and safety promotion. 2003;10(1-2):53-61.

5.Wells S, Mullin B, Norton R, Langley J, Connor J, Jackson R, et al. Motorcycle rider conspicuity and crash related injury: case-control study. Bmj. 2004;328(7444):857.

6.Mahdieh Rad AL, Ansari-Moghaddam A, Mohammadi M, Rashedi F, Ghasemi A. The pattern of road traffic crashes in South East Iran. Global journal of health science. 2016;8(9):149.

7.Mahdian M, Sehat M, Fazel MR, Moraveji A, Mohammadzadeh M. Epidemiology of urban traffic accident victims hospitalized more than 24 hours in a level III trauma center, Kashan county, Iran, during 2012-2013. Archives of trauma research. 2015;4(2).

8.Barros AJ, Amaral RL, Oliveira MSB, Lima SC, Gonçalves EV. Motor vehicle accidents resulting in injuries: underreporting, characteristics, and case fatality rate. Cadernos de saude publica. 2003;19(4):979-86.

9.Graziano PA, Reid A, Slavec J, Paneto A, McNamara JP, Geffken GR. ADHD symptomatology and risky health, driving, and financial behaviors in college: the mediating role of sensation seeking and effortful control. Journal of attention disorders. 2015;19(3):179-90.

10.Kupek E. Beyond logistic regression: structural equations modelling for binary variables and its application to investigating unobserved confounders. BMC medical research methodology. 2006;6(1):13.

11.Harrington D. Confirmatory factor analysis: Oxford university press. USA; 2008.

12.Rabe-Hesketh S, Skrondal A, Pickles A. Generalized multilevel structural equation modeling. Psychometrika. 2004;69(2):167-90.

13.Zhu B, Walter SD, Rosenbaum PL, Russell DJ, Raina P. Structural equation and log-linear modeling: a comparison of methods in the analysis of a study on caregivers' health. BMC Medical Research Methodology. 2006;6(1):49.

14.Sadeghi-Bazargani H, Amiri S, Hamraz S, Malek A, Abdi S, Shahrokhi H. Validity and reliability of the Persian version of Conner's adult ADHD rating scales: observer and self-report screening versions. Journal of Clinical Research \& Governance. 2014;3(1):42-7.

15.SE. CCE. Conners' Adult ADHD Rating Scales: Technical Manual. Toronto, ON: Multi-Health Systems Inc. 2010.

16.Elliott MA, Baughan CJ, Sexton BF. Errors and violations in relation to motorcyclists' crash risk. Accident Analysis \& Prevention. 2007;39(3):491-9.

17.Motevalian SA, Asadi-Lari M, Rahimi H, Eftekhar M, editors. Validation of a persian version of motorcycle rider behavior questionnaire. Annals of Advances in Automotive Medicine/Annual Scientific Conference; 2011: Association for the Advancement of Automotive Medicine.

18.Hair JF, Black WC, Babin BJ, Anderson RE, Tatham RL. Multivariate data analysis (Vol. 6). Upper Saddle River, NJ: Pearson Prentice Hall; 2006.

19.Fan X, Wang L. Effects of potential confounding factors on fit indices and parameter estimates for true and misspecified SEM models. Educational and Psychological Measurement. 1998;58(5):701-35. 20.Jackson DL. Revisiting sample size and number of parameter estimates: Some support for the N: q hypothesis. Structural equation modeling. 2003;10(1):128-41.

21.Taasoobshirazi G, Wang S. The performance of the SRMR, RMSEA, CFI, and TLI: An examination of sample size, path size, and degrees of freedom. Journal of Applied Quantitative Methods. 2016;11(3):31-9.

22.Lee J-Y, Chung J-H, Son B. Analysis of traffic accident size for Korean highway using structural equation models. Accident Analysis \& Prevention. 2008;40(6):1955-63.

23.Fyhri A, Klæboe R. Road traffic noise, sensitivity, annoyance and self-reported health-A structural equation model exercise. Environment International. 2009;35(1):91-7.

24.Alavi. M. Structural Equation Modeling in Health Sciences Education Research: Introducing its Method and Application,. Iranian Journal of Education in medical science,. 2014,;13(6):30-519.

25.Mogadasin M FM. Application of structural equation models reliability and validity estimation psychological tests and assess the reliability and construct validity of the questionnaire (CAARS-S: 
SV) ADHD Adults Diagnosis,. Educational Measurement Schedule, Institute of Humanities and Cultural Studies Comprehensive Human Sciences Portal,. 2013,;3(10):37-103.

26.Pour Ahmad A GI. Modeling Structural Equations in Urban Planning. Specialized magazine of the light,. 2011,;19(76):5-10.

27.Raykov T, Marcoulides GA. A first course in structural equation modeling: Routledge; 2012.

28. Sümer N. Personality and behavioral predictors of traffic accidents: testing a contextual mediated model. Accident Analysis \& Prevention. 2003;35(6):949-64.

29.Albashrawi M, Kartal H, Oztekin A, Motiwalla L. The impact of subjective and objective experience on mobile banking usage: An analytical approach. 2017.

30.Alinia S, Khankeh H, Maddah SSB, Negarandeh R. Barriers of pre-hospital services in road traffic injuries in Tehran: the viewpoint of service providers. International journal of community based nursing and midwifery. 2015;3(4):272.

31.Kim K, Timm N. Univariate and multivariate general linear models: theory and applications with SAS: Chapman and Hall/CRC; 2006.

32.Peden M, Scurfield R, Sleet D, Mohan D, Hyder AA, Jarawan E, et al. World report on road traffic injury prevention. World Health Organization Geneva; 2004.

33.Chin WW, Marcolin BL, Newsted PR. A partial least squares latent variable modeling approach for measuring interaction effects: Results from a Monte Carlo simulation study and an electronic-mail emotion/adoption study. Information systems research. 2003;14(2):189-217.

34.Wetzels M, Odekerken-Schröder G, Van Oppen C. Using PLS path modeling for assessing hierarchical construct models: Guidelines and empirical illustration. MIS quarterly. 2009:177-95.

35. Weafer J, Camarillo D, Fillmore MT, Milich R, Marczinski CA. Simulated driving performance of adults with ADHD: Comparisons with alcohol intoxication. Experimental and clinical psychopharmacology. 2008;16(3):251.

36. Shyhalla K. Alcohol involvement and other risky driver behaviors: effects on crash initiation and crash everity. Traffic injury prevention. 2014;15(4):325-34.

37. Weiss HB, Kaplan S, Prato CG. Analysis of factors associated with injury severity in crashes involving young New Zealand drivers. Accident Analysis \& Prevention. 2014;65:142-55.

38.Violato C, Hecker KG. How to use structural equation modeling in medical education research: A brief guide. Teaching and learning in medicine. 2007;19(4):362-71. 